\title{
Review Article \\ Bedside Assessment of Tissue Oxygen Saturation Monitoring in Critically Ill Adults: An Integrative Review of the Literature
}

\author{
Carol Diane Epstein ${ }^{1}$ and Karen Toby Haghenbeck ${ }^{2}$ \\ ${ }^{1}$ College of Health Professions, Lienhard School of Nursing, Pace University, Office 319, 861 Bedford Road, \\ Pleasantville, NY 10570, USA \\ ${ }^{2}$ College of Health Professions, Lienhard School of Nursing, Pace University, Office L308, 861 Bedford Road, \\ Pleasantville, NY 10570, USA \\ Correspondence should be addressed to Carol Diane Epstein; cepstein@pace.edu
}

Received 3 January 2014; Revised 23 March 2014; Accepted 3 April 2014; Published 8 May 2014

Academic Editor: Stephen M. Pastores

Copyright (C) 2014 C. D. Epstein and K. T. Haghenbeck. This is an open access article distributed under the Creative Commons Attribution License, which permits unrestricted use, distribution, and reproduction in any medium, provided the original work is properly cited.

\begin{abstract}
Objective. Tissue oxygen saturation $\left(\mathrm{StO}_{2}\right)$ monitoring is a noninvasive technology with the purpose of alerting the clinician of peripheral hypoperfusion and the onset of tissue hypoxia. This integrative review examines the rigor and quality of studies focusing on $\mathrm{StO}_{2}$ monitoring in adult critically ill patients. Background. Clinicians must rapidly assess adverse changes in tissue perfusion while minimizing potential complications associated with invasive monitoring. The noninvasive measurement of tissue oxygen saturation is based on near-infrared spectroscopy (NIRS), an optical method of illuminating chemical compounds which absorb, reflect, and scatter light directed at that compound. Methods. An integrative review was conducted to develop a context of greater understanding about complex topics. An Integrative review draws on multiple experimental and nonexperimental research methodologies. Results. Fourteen studies were graded at the $\mathrm{C}$ category. None reported the use of probability sampling or demonstrated a cause-and-effect relationship between $\mathrm{StO}_{2}$ values and patient outcomes. Conclusions. Future research should be based on rigorous methods of sampling and design in order to enhance the internal and external validity of the findings.
\end{abstract}

\section{Introduction}

Tissue oxygen saturation $\left(\mathrm{StO}_{2}\right)$ monitoring is a relatively new technology that has been reported to function as an early warning sign of peripheral hypoperfusion and the onset of tissue hypoxia [1-4]. Also called a tissue spectrometer, $\mathrm{StO}_{2}$ technology is based on near-infrared spectroscopy (NIRS), an optical method of illuminating chemical compounds which absorb, reflect, and scatter light directed at that compound. NIRS technology has its origins a century ago, and its application to the human body was developed in the 1970s by Jobsis for the invasive monitoring of cerebral and cardiac oxygenation [5]. In the case of $\mathrm{StO}_{2}$ monitoring, the measured chromophore compounds include oxyhemoglobin, deoxyhemoglobin, and total hemoglobin concentrations in the muscle tissue bed. The underlying rationale for bedside $\mathrm{StO}_{2}$ monitoring is its potential capacity to alert the clinician that peripheral blood flow is being redistributed to vital organs as the normal balance between the proportions of oxyhemoglobin and deoxyhemoglobin in the peripheral tissues undergoes adverse changes. Initially used as a marker of the adequacy of resuscitation in patients with hemorrhagic shock, $\mathrm{StO}_{2}$ monitoring has attracted interest because of its noninvasive and real time nature, as well as its potential utility in research efforts designed to reduce morbidity and mortality $[6,7]$. The purpose of this integrative review is to review the quality and rigor of studies employing $\mathrm{StO}_{2}$ monitoring at the bedside in the intensive care unit (ICU).

\section{Methods}

The methodology for this integrative review is based on the model recommended by Whittemore and Knafl [8]. This approach draws on both experimental and nonexperimental 
research as well as theoretical, historical, qualitative, methodological, and expert empirical perspectives from the scientific literature in order to develop a context of greater understanding about a complex topic of concern. The construct of tissue hypoxia seems well suited to this type of review. After more than a century of research in multiple disciplines, definition and validation of the phenomenon remain elusive, complex, and difficult to operationalize in research studies. For example, in a study of peripheral vasoconstriction on $\mathrm{StO}_{2}$ values in human volunteers, Lima and colleagues recently cautioned that the effect of thenar skin circulation on $\mathrm{StO}_{2}$ signals may mislead the clinician into concluding that tissue hemoglobin is undergoing oxygen desaturation when it is not [9].

Whittemore and Knafl proposed several strategies to enhance rigor and avoid subjective bias in the development of an integrative review. During the problem identification stage, the variables of interest should be specified, for example, concepts, target population, and health care problem. The scientific literature related to the broad topic of NIRS consists of at least 60,000 studies and reviews. For the purpose of this review, the concepts of interest are focused on the following problem statement: what is the quality of the scientific evidence on $\mathrm{StO}_{2}$ data in critically ill adults, generated by the technology of near-infrared spectroscopy (NIRS)?

The next step of an integrative review is to select an appropriate sampling frame, for example, empirical studies, inclusion of theoretical literature, historical perspectives, terms used in the literature search, the databases used, additional search strategies, identification of articles in reference lists, and the inclusion and exclusion criteria for determining relevant primary sources. A search for articles published in English from 1996 to 2013 and indexed in CINAHL, MEDLINE, Joanna Briggs Institute, and Google Scholar databases was performed using the following key terms: tissue hypoxia, tissue oxygenation saturation $\left(\mathrm{StO}_{2}\right)$, critically ill adults in the intensive care unit (ICU), serum lactate, mortality, and multiple organ dysfunction syndrome (MODS). Studies which met at least four of these criteria were included for review. The literature search focused specifically on studies consisting of sample populations of critically ill adult patients. As recommended by Whittemore and Knafl, citations in retrieved journal articles were examined for possible omission of relevant articles. Research abstracts were not considered for review. Exclusion criteria consisted of studies using NIRS monitoring of pediatric patients and patients receiving cerebral oxygenation monitoring, as these sampling frames were not consistent with our specific topic of interest. The authors independently reviewed and graded each study, using the American Association of CriticalCare Nurses' (AACN) Evidence-Leveling Hierarchy (Table 1) [10]. When the authors shared their ratings, they continued discussion until consensus was reached.

\section{Background}

3.1. Near-Infrared Spectroscopy: A Method for Monitoring Tissue Oxygen Saturation. Near-infrared spectroscopy (NIRS) is an optical technology which has been exploited for monitoring tissue oxygen saturation at the bedside [11]. In his comprehensive review, Chance dates the origins of spectroscopy, which he called the "optical method," to Otto Warburg in the 1930s [12]. Spectroscopy was used to study alterations in the light-absorbing and light-reflecting characteristics of substrates as they undergo chemical changes. As light is directed at an organic compound in the body, such as adenosine triphosphate (ATP), the compound absorbs that light and loses its intensity at a known rate, known as attenuation. Therefore, the identity and the concentration of an unknown compound can also be quantified based on known characteristics. Pioneering work in NIRS spectroscopy by Chance and Williams using reflectance probes, then called reflectance spectrophotometry, produced descriptions of differential optical light-absorbing characteristics of cytochromes in the respiratory chain during normal oxidative phosphorylation as well as during conditions of hypoxia and anoxia on isolated mitochondria [13]. At this point in history, scientists had devised dual wavelength monitoring to monitor oxygen uptake when cytochromes were exposed to variations in oxygen availability and adenosine diphosphate (ADP) concentration. The next large step was to utilize NIRS to study cytochrome function in intact brains of awake, whole animals and to probe whether there was a critical $\mathrm{PO}_{2}$ at which point ATP synthesis declines irreversibly [14]. The original application of NIRS to the human body was developed by Jobsis in the 1970s, specifically in the monitoring of cerebral and cardiac oxygenation [15]. When NIRS is used to study biological tissues, such as the chromophore hemoglobin, data generated by this technology is calculated by the differences in the light-absorbing and light-reflecting characteristics of oxyhemoglobin and deoxyhemoglobin, which in turn provide information about changes in hemoglobin concentration [5]. Chance referred to spectroscopic analysis of changes in hemoglobin concentration as "tissue hemoglobinometry" [12].

Across the full electromagnetic spectrum (EMS) of light, visible light and our ability to see color lie in the midspectrum range of 400 to 700 nanometers (nm) [16]. The near-infrared light spectrum ranges from $700 \mathrm{~nm}$ to $1000 \mathrm{~nm}$, above (or visually speaking, to the right of) visible light on the EMS spectrum, and the wavelengths approximately 650 to $900 \mathrm{~nm}$ are used in the clinical applications of NIRS technology. The NIRS technology is primarily used to measure regional cerebral oxygen saturation $\left(\mathrm{rSO}_{2}\right)$. Nearinfrared light is able to access up to a tissue depth of 8 centimeters $(\mathrm{cm})$, whereas visible light can penetrate no deeper than one $\mathrm{cm}$ [5]. The NIRS instrumentation light source is a laser diode. There are currently 3 types of spectrometers: continuous wave, time-of-flight, and frequency domain. Continuous wave NIRS is the most commonly used noninvasive spectrometer in research and clinical settings. The instrumentation consists of at least 3 wavelengths, but most devices have 4 in order to differentiate more accurately among the different types of hemoglobin. This type of NIRS is used in measurement of neonatal cerebral blood flow and volume with an oxygen tracer. Cerebral venous oxygenation can also be measured with NIRS by several maneuvers, for 
TABLE 1: AACN’s new evidence-leveling system.

Level

A Meta-analysis of multiple controlled studies or metasynthesis of qualitative studies with results that consistently support a specific action, intervention, or treatment.

B Well-designed controlled studies, both randomized and nonrandomized, with results that consistently support a specific action, intervention, or treatment.

C Qualitative studies, descriptive or correlational studies, integrative reviews, systematic reviews, or randomized controlled trials with inconsistent results.

D Peer-reviewed professional organizational standards, with clinical studies to support recommendations.

E Theory-based evidence from expert opinion or multiple case reports.

M Manufacturer's recommendations only.

[10].

example, gentle occlusion of the jugular vein, manipulation of cerebral blood volume by altering ventilation, or by gravity, as the infant's body is shifted to increase venous blood volume. Beyond the neonatal ICU, NIRS has been used to measure regional tissue oxygen saturation in many types of conditions, including adult non-ICU patients who were (1) undergoing esophageal and colorectal cancer surgery $[17,18]$; (2) at risk for postoperative abdominal surgical infection [19]; and (3) experiencing intermittent claudication [20].

Noninvasive measurement of skeletal muscle tissue oxygen saturation of hemoglobin $\left(\mathrm{StO}_{2}\right)$ by NIRS is based on wavelength analysis of 3 differential forms of hemoglobin, including oxyhemoglobin, deoxyhemoglobin, and total hemoglobin [21]. The spectrometer is programmed with an algorithm derived from 4 wavelengths of light at 680, 720, 760 , and 800 nanometers $(\mathrm{nm})$, respectively, reflecting the interaction of optical light paths absorbed by chromophores, including the following: (1) oxyhemoglobin concentration $\left[\mathrm{HbO}_{2}\right]$; (2) deoxyhemoglobin concentration [HHb]; (3) total hemoglobin concentration $\left[\mathrm{HbO}_{2}\right]+[\mathrm{HHb}]$; and (4) $\mathrm{StO}_{2}$, tissue hemoglobin oxygen saturation $\left[\mathrm{HbO}_{2}\right] /$ $\left(\left[\mathrm{HbO}_{2}\right]+[\mathrm{HHb}]\right)$. The final $\mathrm{StO}_{2}$ percentage value is displayed on a monitor.

The $\mathrm{StO}_{2}$ light probe is most often placed adhesively on the thenar eminence of the hand, that is, the thumb muscle. Normal $\mathrm{StO}_{2}$ values in human volunteers have been reported to average $87 \pm 6 \%$ in two separate studies [22, 23]. Under conditions of intact autoregulation, the peripheral microcirculation in the muscle should vasoconstrict during the onset of shock in order to shunt blood flow to critical organs; theoretically, a decrease in $\mathrm{StO}_{2}$ should be displayed on the monitor immediately [24-26]. Clinicians who work in intensive care, the emergency department, operating suites, and postanesthesia care would have bedside access to this information while invasive devices are placed. In order to evaluate the scientific literature on the clinical utility of $\mathrm{StO}_{2}$ monitoring, we conducted a review of the literature focusing on the use of the $\mathrm{StO}_{2}$ monitoring in studies of high acuity and critically ill patients.

3.2. Review of the Literature: Results. There are 3 types of spectrometers cited in the literature search: (1) the EQUANOX Model 7600 Regional Oximetry System (Nonin
Medical Inc., Plymouth, MN, USA), (2) the InSpectra tissue spectrometer (Hutchinson Technology Inc., BioMeasurement Division, Hutchinson, MN, USA), and (3) the INVOS 5100C Cerebral/Somatic Oximeter (Covidien, Dublin, Ireland). The EQUANOX Model 7600 Regional Oximetry System has been used in studies of outpatient problems such as sleep apnea and among community patients subjected to high altitude conditions. The INVOS 5100C Cerebral/Somatic Oximeter was specifically applied to neonatal patients and head-injured patients receiving NIRS monitoring of cerebral oxygenation. The InSpectra tissue spectrometer was the only device used for ICU adult patients at risk for tissue hypoxia.

The American Association of Critical-Care Nurses' (AACN) Evidence-Leveling Hierarchy (Table 1) [10] was used to evaluate the quality and rigor of the study designs. A literature search identified 14 studies for final analysis (Table 2). Review of each study was carried out independently by the authors (Carol Diane Epstein and Karen Toby Haghenbeck) and then mutually by an iterative process. All studies were leveled at the C category and described by the AACN's Evidence-Based Practice Work Group as "qualitative studies, descriptive or correlational studies, integrative reviews, systematic reviews, or randomized controlled trials with inconsistent results" [10]. All study designs were characterized as observational, retrospective, correlational, or prospective in nature. None reported the use of probability sampling, random sampling of subjects, or random assignment of subjects. The study strengths and limitations were identified. Special attention was given to the degree of manufacturer support for the implementation of the research and whether mention was made of the interpretation of data by manufacturer representatives prior to publication.

3.3. Studies of Trauma Patients. Five studies of injured patients utilized prospective, retrospective, and observational designs in which a predetermined $\mathrm{StO}_{2}$ cutoff value functioned as the intervening variable and patient outcomes such as multiple organ dysfunction syndrome (MODS) and mortality served as dependent variables (Table 2). Beilman and colleagues [27] conducted a multicenter, retrospective, post hoc analysis of 356 patients (Table 2, Study 1) enrolled in a larger study (Table 2, Study 3) [7]. In the post hoc analysis, the effect of hypothermia on patient outcome was 


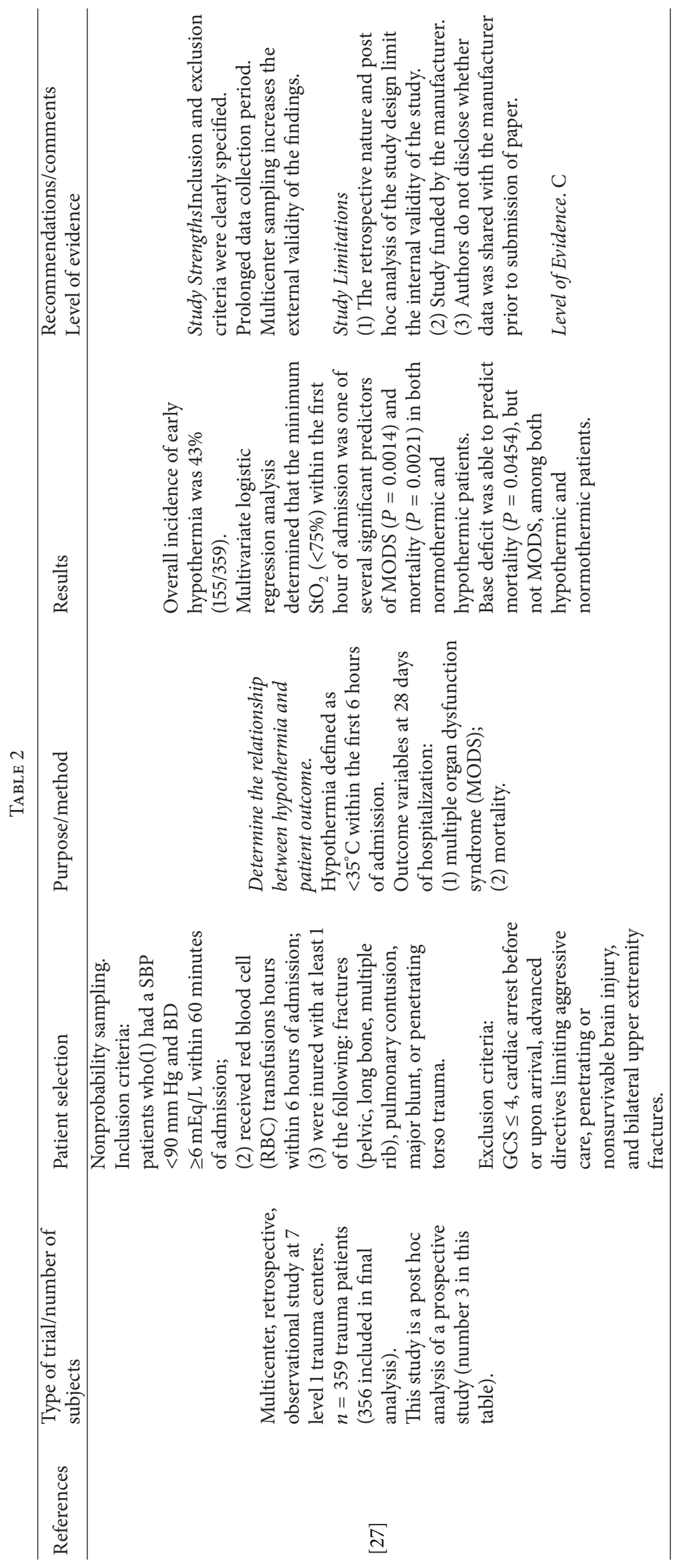




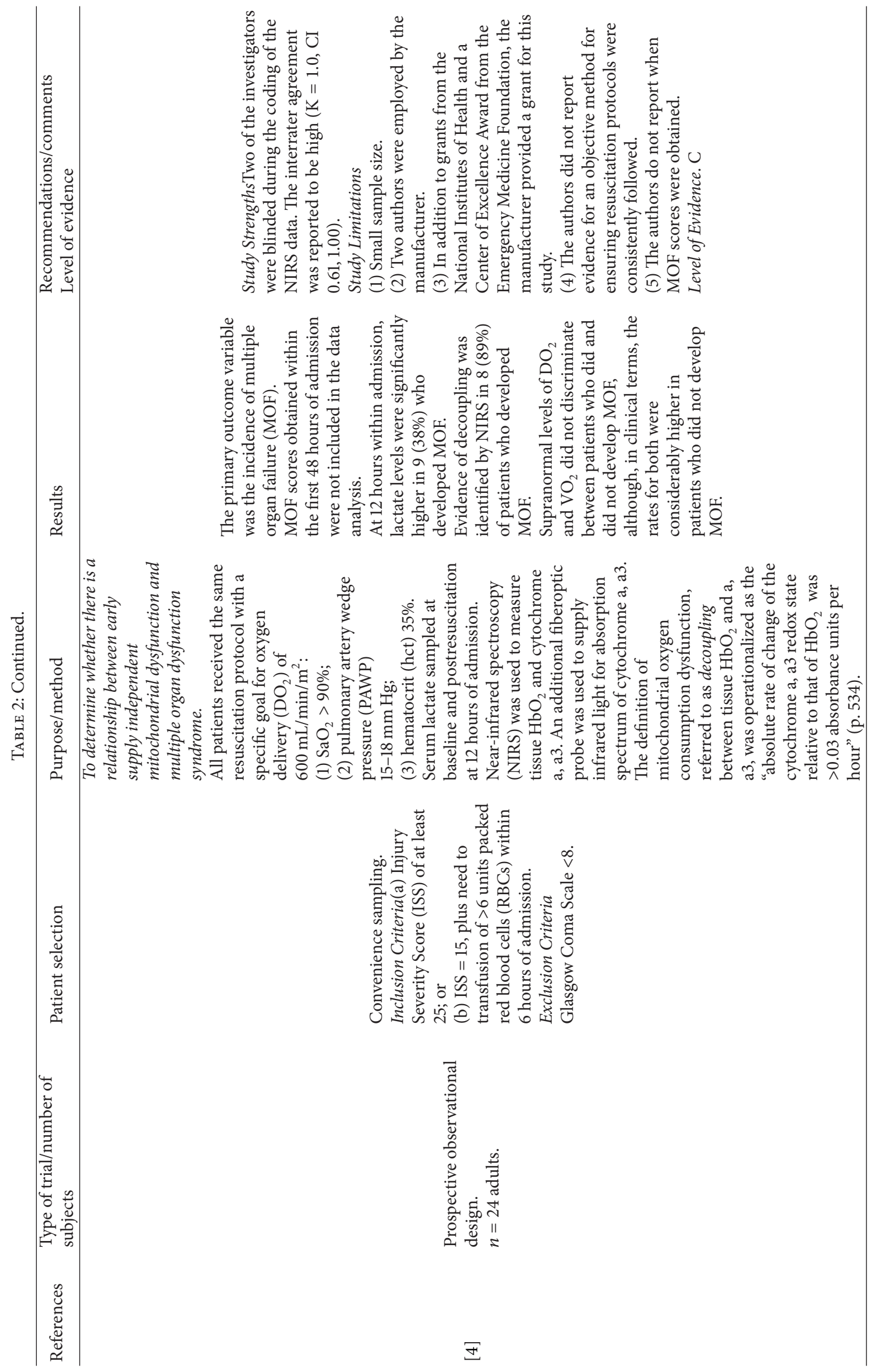




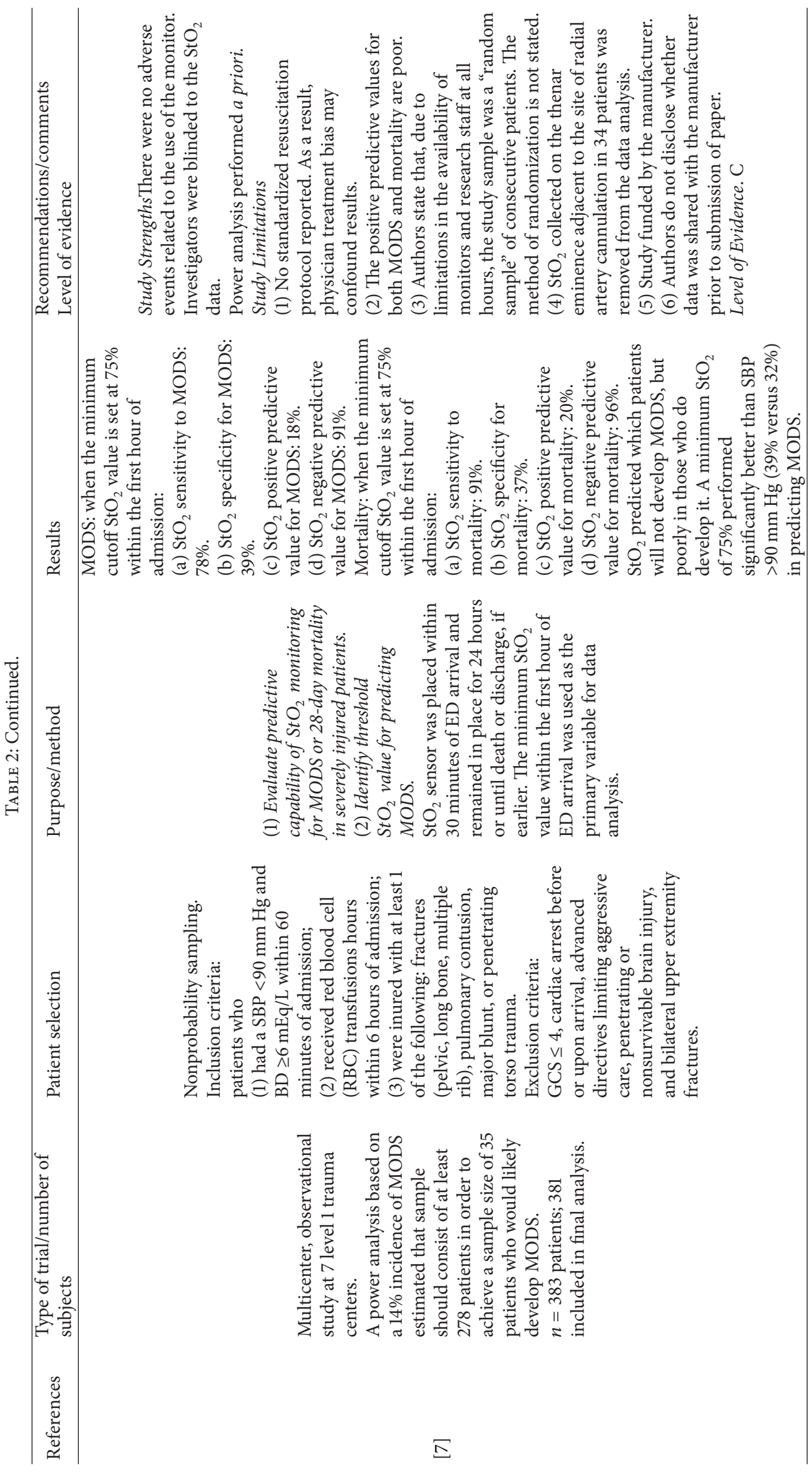




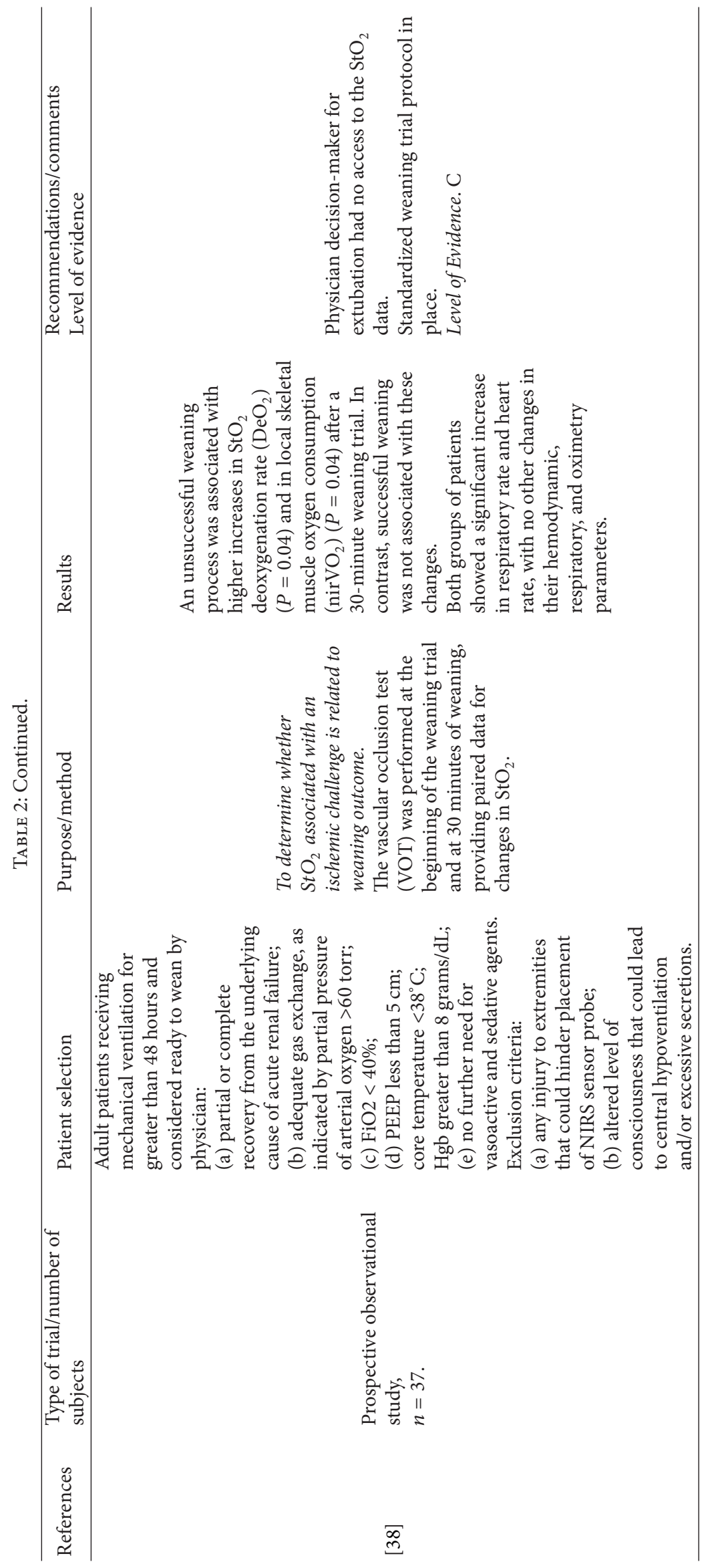




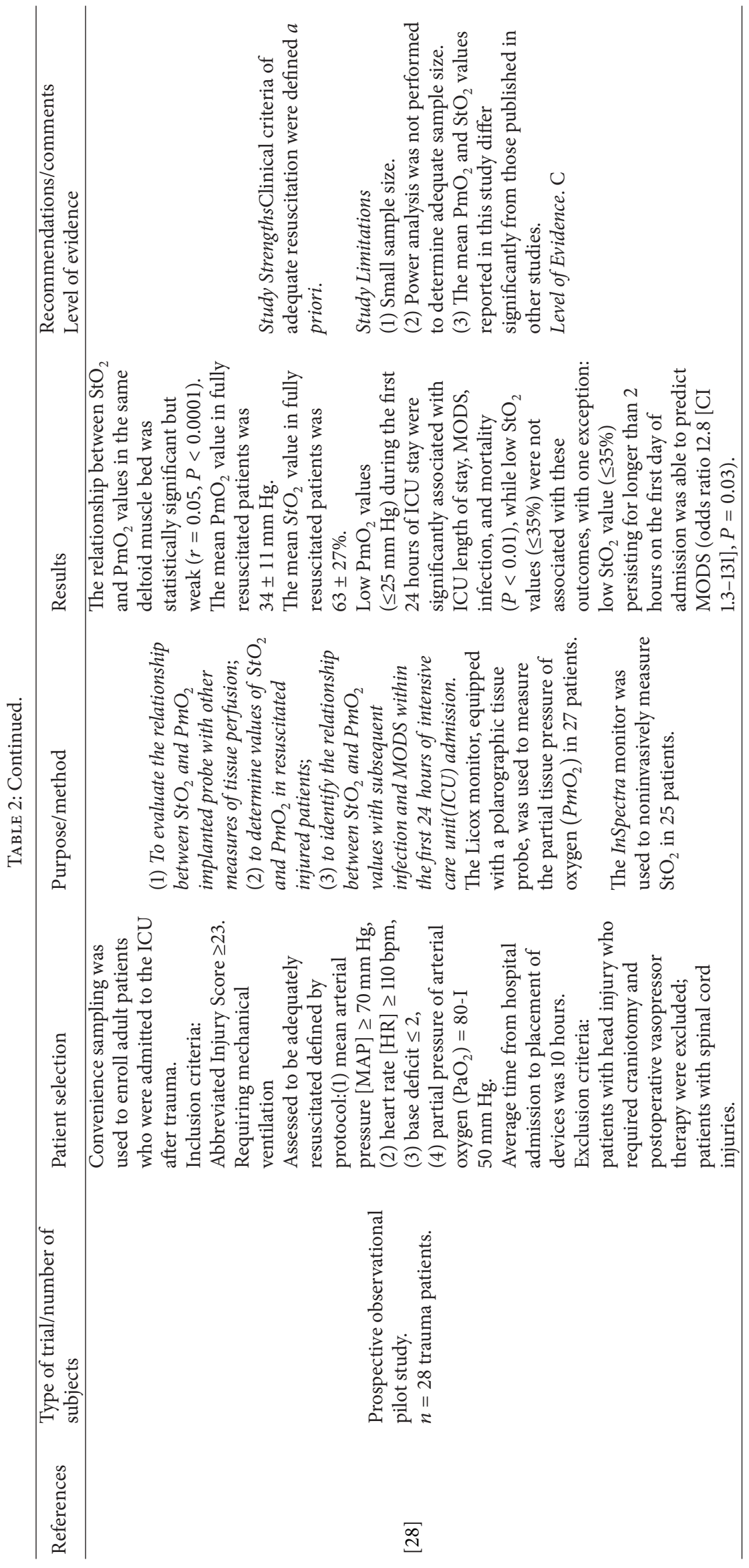



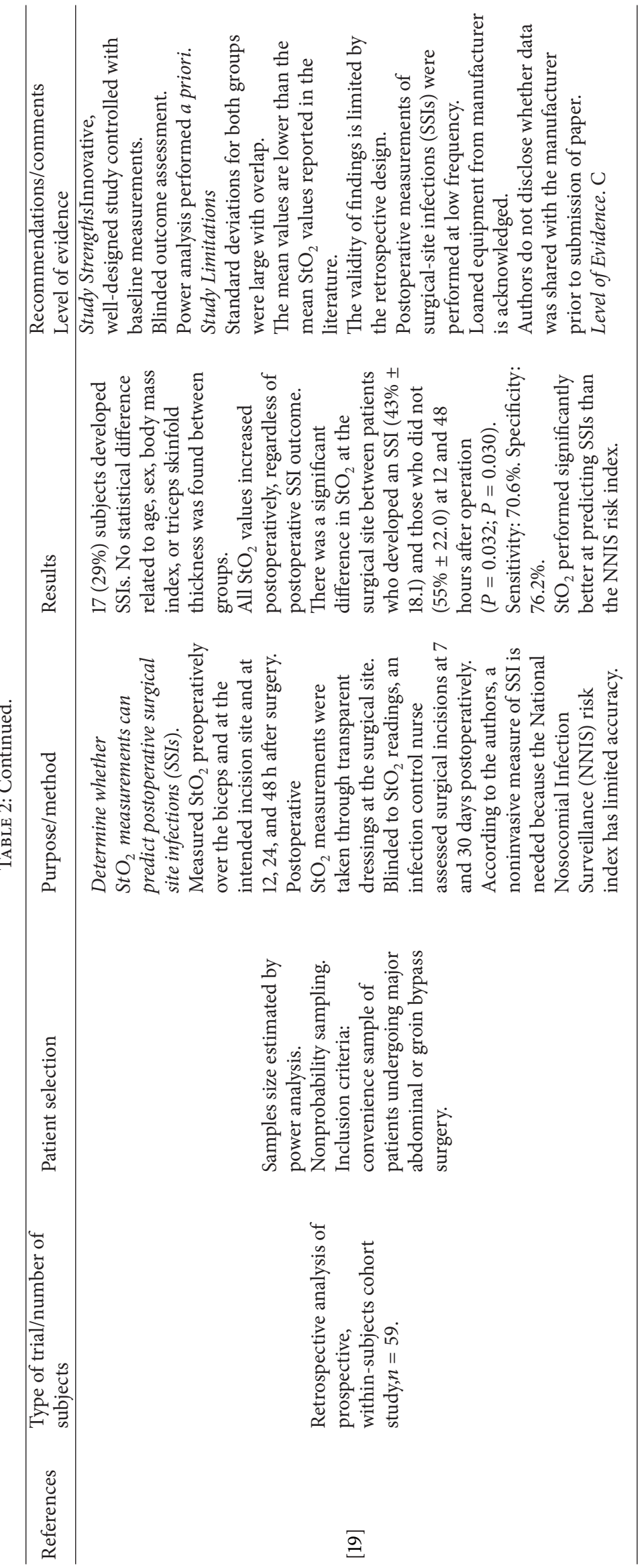


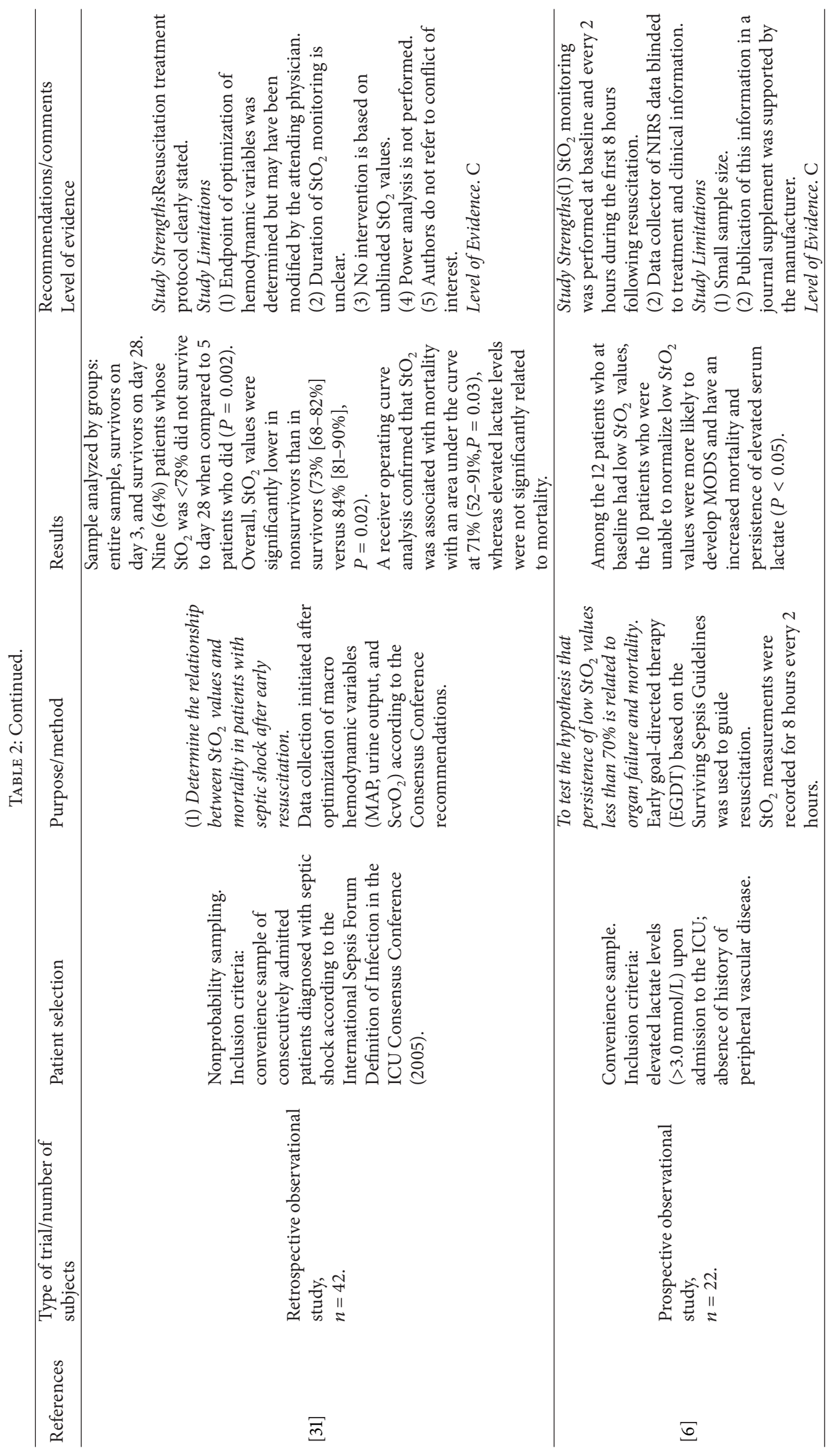




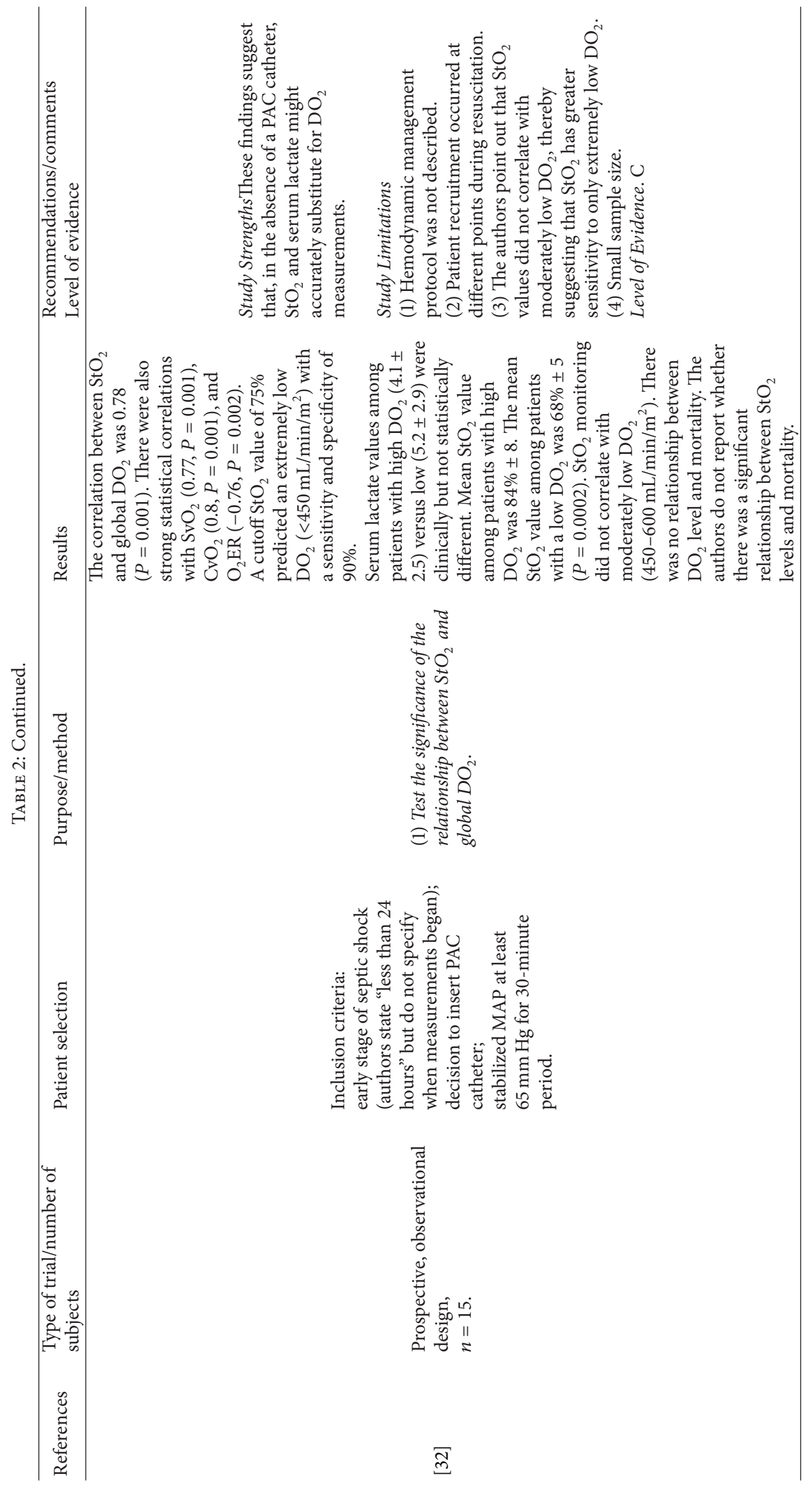



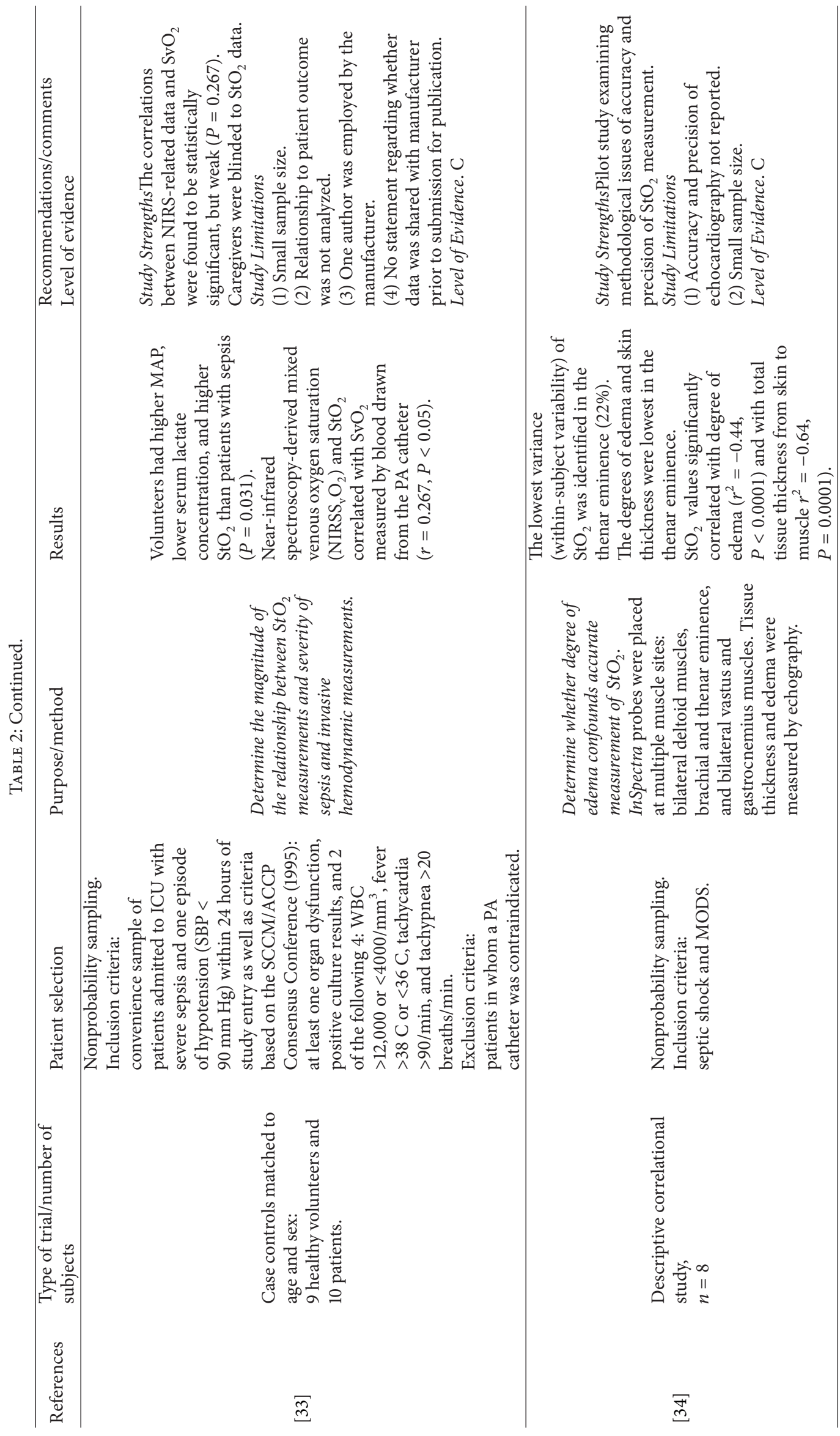


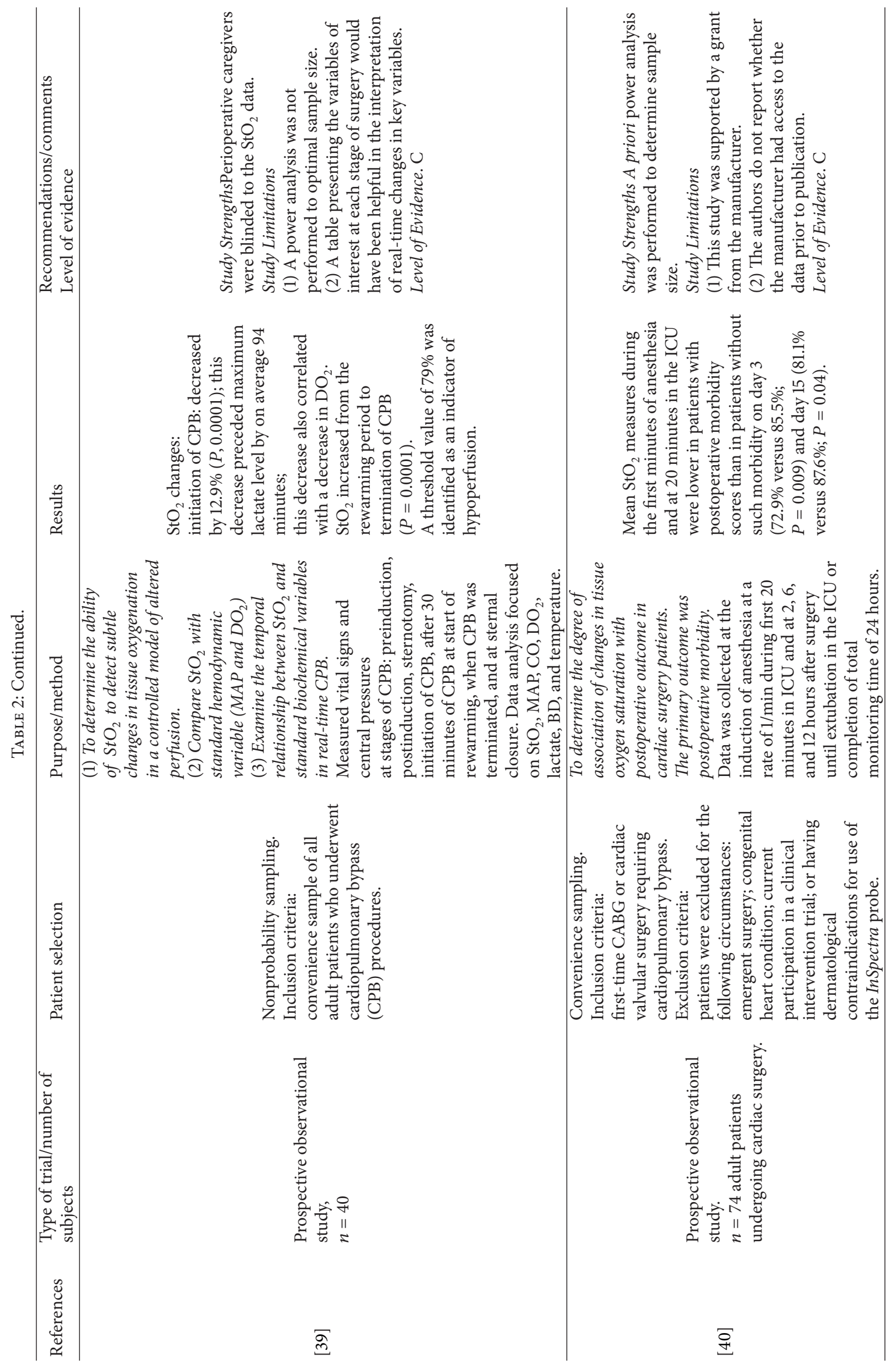




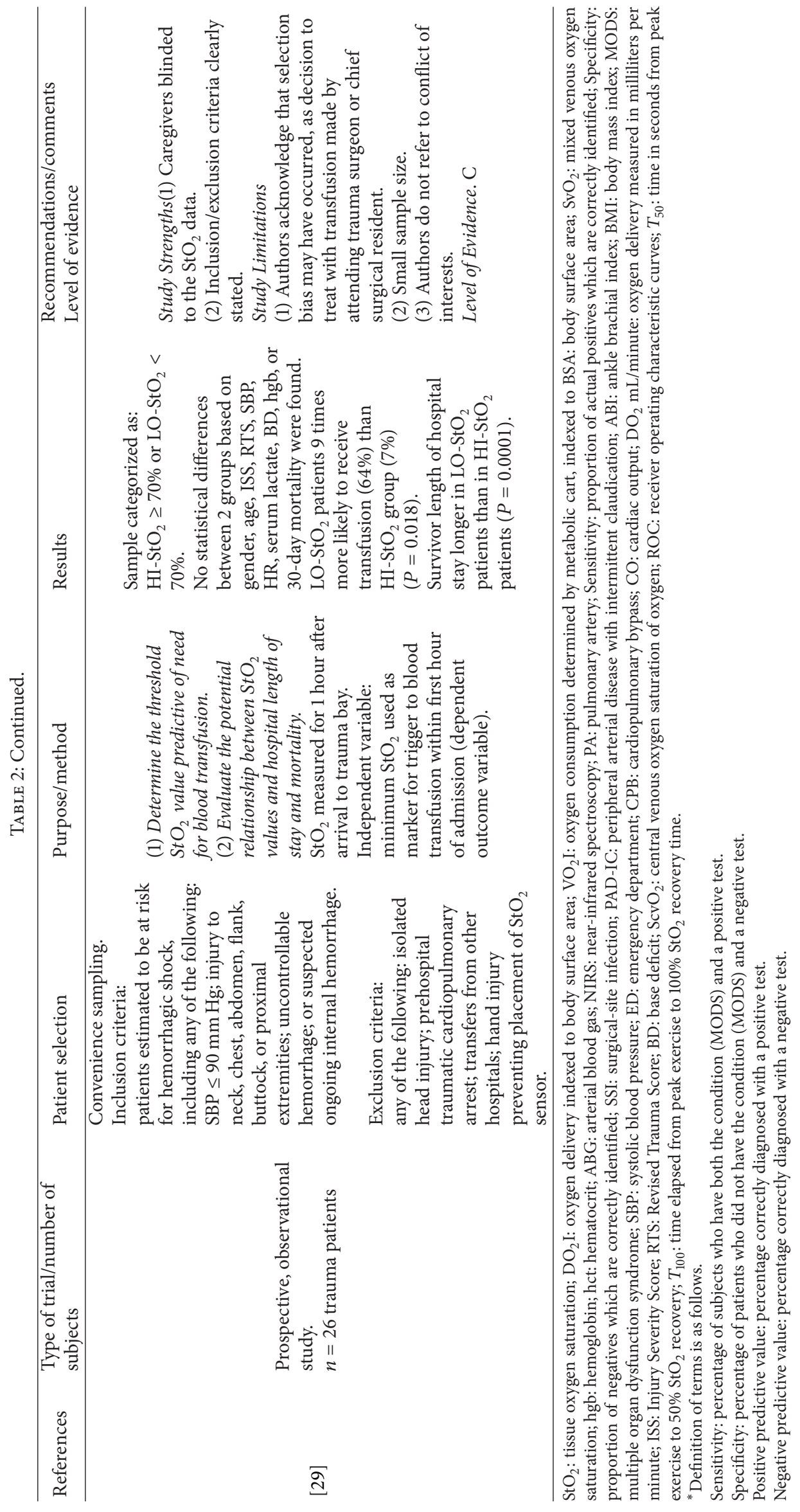


examined, based on a $\mathrm{StO}_{2}$ cutoff value of $75 \%$. Multivariate logistic regression analysis determined that the minimum $\mathrm{StO}_{2}(<75 \%)$ within the first hour of admission was one of several significant predictors of $\operatorname{MODS}(P=0.0014)$ and mortality $(P=0.0021)$ in both normothermic and hypothermic patients. The minimum $\mathrm{StO}_{2}$ values are not reported, with the exception of confidence intervals of $74 \%$ $(62 \%$ to $89 \%)$. Elevated base deficit was able to predict mortality $(P=0.0454)$, but not MODS, among both hypothermic and normothermic patients.

In the prospective study of the same patients (Table 2, Study 3), Cohn and coworkers sought to identify the threshold $\mathrm{StO}_{2}$ value for predicting MODS and mortality as well as the strength of its ability to predict these outcomes in 381 trauma patients [7]. A $\mathrm{StO}_{2}$ value of $75 \%$ was determined empirically from the data analysis. The positive predictive values for MODS and mortality were $18 \%$ and $20 \%$, respectively. That is, $\mathrm{StO}_{2}$ values less than $75 \%$ accurately predicted MODS and patient death only $20 \%$ of the time. The negative predictive value is the probability that subjects who did not develop MODS or die truly did not; in this case, $\mathrm{StO}_{2}$ values performed well at $91 \%$ and $95 \%$, respectively. The clinical implications from the findings of this negative predictive value suggest that $\mathrm{StO}_{2}$ values greater than $75 \%$ indicate the absence of tissue hypoperfusion and, possibly, tissue hypoxia. Yet the positive predictive value of only $20 \%$, when $\mathrm{StO}_{2}$ values fall below 75\%, suggests that the possible causes and interpretation of data are either inaccurate, unclear, or subject to theoretical or technological error.

Cairns and coworkers [4] (Table 2, Study 2) were the first to investigate the use of NIRS in severely traumatized patients following early goal directed therapy based on supranormal oxygen transport goals within the first 12 hours of admission. They proposed a novel hypothesis of the relationship between early oxygen supply-independent mitochondrial dysfunction and MODS in trauma patients. In other words, these investigators hypothesize that the construct of oxygen supply-dependent oxygen consumption can be operationalized and identified at the level of the mitochondria during the onset of tissue hypoxia. In order to measure the "decoupling" oxidative changes in cytochrome a, a3, an additional fiber-optic probe was used to supply infrared light for the cytochrome's light absorption spectrum characteristics. However, the authors state that the underlying empirical support for the definition of "decoupling" was derived from unpublished data. The authors defined this event as occurring when the relative rates of change in absorption of oxyhemoglobin $\left(\mathrm{HbO}_{2}\right)$ and cytochrome a, a3 no longer rise and fall in concert. Evidence of decoupling was found to be statistically significant in $8(89 \%)$ of the patients who developed MODS, compared to $13 \%$ of patients who did not. Lactate levels were significantly higher in 9 (38\%) who developed MODS ( $3.6 \pm 0.3$ versus $1.7 \pm 0.2)$.

Ikossi and colleagues studied $\mathrm{StO}_{2}$ values in 28 trauma patients who were assessed to be adequately resuscitated by objective criteria following ICU admission (Table 2, Study 5) [28]. They also compared correlations between measurements of $\mathrm{StO}_{2}$ and the partial tissue pressure of oxygen in $\left(\mathrm{PmO}_{2}\right)$, an invasive probe-equipped device inserted into the deltoid muscle. The authors propose that their findings established "normal" values of the mean $\mathrm{StO}_{2}$ values in fully resuscitated patients; however, the mean $\mathrm{StO}_{2}$ of $63 \% \pm 27$ is relatively low compared to findings subsequently reported in normal subjects $[22,23]$, while the standard deviation (SD) is large. Low $\mathrm{StO}_{2}$ values $(<35 \%)$ persisting for longer than 2 hours on the first day of admission were able to predict MODS (odds ratio 12.8 [CI 1.3-131], $P=0.03$ ). In spite of these significant results, the authors do not adequately address possible reasons why fully resuscitated patients should have such low $\mathrm{StO}_{2}$ values.

Smith and coworkers studied the utility of $\mathrm{StO}_{2}$ as a trigger for blood transfusion in 22 trauma patients using a cutoff $\mathrm{StO}_{2}$ value of $70 \%$ (Table 2, Study 14) [29]. The cutoff value was determined empirically by logistic regression following data collection. In this study, the $\mathrm{StO}_{2}$ value was operationalized as the independent variable, and blood transfusion was the dependent variable. $\mathrm{StO}_{2}$ measurements were made within one hour of admission; patients with low $\mathrm{StO}_{2}$ values were 9 times as likely to receive transfusion $(P=$ $0.018)$. A strength of this study included blinding caregivers to the $\mathrm{StO}_{2}$ values, while the investigators acknowledge that physician bias for ordering blood transfusions may have occurred. Based on three deaths, findings from this study for the use of $\mathrm{StO}_{2}$ monitoring yielded a weak positive predictive value of $27 \%$ and a strong negative predictive value of $93 \%$.

3.4. Studies of General Critically Ill Patients. Studies based on heterogeneous samples of ICU patients pose special challenges in interpretation of findings. In spite of this limitation, Lima et al. conducted a well-designed study by performing $\mathrm{StO}_{2}$ measurements in 22 critically ill patients with elevated serum lactate levels during the first 8 hours of ICU admission (Table 2, Study 8) [6]. All but three patients were diagnosed with varied shock states, including septic, cardiogenic, hypovolemic, hemorrhagic, and traumatic shock. A cutoff $\mathrm{StO}_{2}$ value of $70 \%$ was used to determine whether $\mathrm{StO}_{2}$ monitoring would demonstrate a relationship with the incidence of MODS and mortality. A major strength of this study was the blinding of the data collector to patient information and treatment. Among the 12 patients who at baseline had low $\mathrm{StO}_{2}$ values, ten patients were unable to normalize low $\mathrm{StO}_{2}$ values and were more likely to develop MODS, have an increased mortality, and have persistence of elevated serum lactate levels $(P<0.05)$.

3.5. Studies of Septic Patients. Studies of septic patients are inherently difficult to design and implement because the sampling start time frame may be difficult to identify [30]. The diagnostic criteria for the Surviving Sepsis Campaign, for example, are applied to the conditions of sepsis, severe sepsis, sepsis-induced hypotension, septic shock, and sepsisinduced hypoperfusion. Researchers must address the need to define a priori the inclusion/exclusion criteria as well as the time frames for study entry. For example, should one initiate the study early in the septic process or delay until resuscitation is thought to be complete? Three studies of septic patients were based on $\mathrm{StO}_{2}$ measurements (Table 2, 
Studies 7, 9, and 10). Leone and colleagues conducted a retrospective, observational study of 42 consecutive patients diagnosed with septic shock (Study 7) [31]. $\mathrm{StO}_{2}$ measurements were initiated when augmentation of global hemodynamic variables "seemed optimal, according to the decision of the attending physician (page 367)." Thus, the start time frame is unclear, and the duration of monitoring also remains uncertain. Overall, $\mathrm{StO}_{2}$ values were significantly lower in nonsurvivors than in survivors (73\% [68-82\%] versus $84 \%$ [81-90\%], $P=0.02$ ). A receiver operating curve analysis confirmed that $\mathrm{StO}_{2}$ was associated with mortality with an area under the curve at $71 \%(52-91 \%, P=0.03)$, whereas elevated lactate levels were not found to be significantly related to patient death.

Mesquida and coinvestigators tested the potential relationship between oxygen delivery $\left(\mathrm{DO}_{2}\right)$ and $\mathrm{StO}_{2}$ values in 15 septic patients who were enrolled in the study within 24 hours of demonstrating early signs of sepsis and following a decision to place a pulmonary artery catheter (PAC) (Study 9) [32]. The timing of measurements was not specified. While the correlation between $\mathrm{DO}_{2}$ and $\mathrm{StO}_{2}$ was fairly strong at $0.78(P=0.001)$, there was no significance detected for either value with the incidence of mortality. An interesting finding was the magnitude of the relationship between $\mathrm{StO}_{2}$ and invasive measurements of $\mathrm{SvO}_{2}(0.77, P=0.001)$ and $\mathrm{CvO}_{2}$ $(0.8, P=0.001)$, thereby suggesting that $\mathrm{StO}_{2}$ could serve as a proxy for estimating mixed venous oxygen saturation of hemoglobin.

Mulier and colleagues also investigated the degree to which global invasive oxygen transport measurements and severity of sepsis correlated with $\mathrm{StO}_{2}$ values (Study 10) [33]. Inclusion criteria were strictly defined, as was timing of measurements. Caregivers were blinded to the $\mathrm{StO}_{2}$ data. The correlations between NIRS-related data and $\mathrm{SvO}_{2}$ were found to be statistically significant, but weak $(P=0.267)$. The relationship to patient outcome was not analyzed. Measurements of $\mathrm{StO}_{2}$, serum lactate, hemoglobin, and oxygen consumption $\left(\mathrm{VO}_{2}\right)$ were also carried out in 9 healthy volunteers; however, the $\mathrm{StO}_{2}$ values were reported in general terms in which they were "higher" than in septic patients (page 517).

3.6. Methodological Studies. Emergence of new technologies commonly spawns innovative exploration of potential uses that were not initially associated with the device. In physiologic studies, the validity of measurements is commonly referred to as the accuracy of the phenomenon of interest, in this case, tissue hypoxia. The reliability of measurements, otherwise known as precision, quantifies whether the difference between two measurements separated by a time interval reflects a real change. Methodological studies often examine the accuracy and precision of measurements, as well as the degree to which intervening variables may interfere with them.

The development of third-space interstitial edema among septic patients as well as its influence on the variability of $\mathrm{StO}_{2}$ measurements was examined by Poeze (Table 2, Study 11) [34]. In order to explore which muscle sites are most accurate for measuring $\mathrm{StO}_{2}$, InSpectra sensors were adhesively placed in 8 septic patients at multiple muscle sites: bilateral deltoid muscles, bilateral brachial, the thenar eminence, and bilateral vastus and gastrocnemius muscles. Tissue thickness and the degree of edema were measured by echocardiography. The degrees of edema and skin thickness were found to be the lowest in the thenar eminence. $\mathrm{StO}_{2}$ values significantly correlated with degree of edema $\left(r^{2}=-0.44, P<0.0001\right)$ and with total tissue thickness from skin to muscle $\left(r^{2}=-0.64\right.$, $P=0.0001)$.

Vascular occlusive testing (VOT) is used to help identify tissue hypoperfusion and to assess dynamic changes in microcirculation in conjunction with $\mathrm{StO}_{2}$ monitoring [35]. VOT provides an ischemic challenge to peripheral tissues allowing analysis of tissue response when occlusion is released. The VOT was used in healthy volunteers to examine the relationship between the VOT and $\mathrm{StO}_{2}$ measurements $[35,36]$. Shapiro and colleagues performed VOT on patients with sepsis syndromes and organ dysfunction in emergency department patients [37]. However, the technique for using VOT has not been standardized [36]. In a sample of healthy volunteers, Suhaimi and coworkers [35] reported rapidly inflating the sphygmomanometer to $40 \mathrm{mmHg}$ above the baseline systolic blood pressure (SBP), with inflation lasting over 10-30 seconds, occlusion for 3 minutes, followed by rapid deflation. Gómez et al. [36] reported that, in healthy volunteers, inflation of a blood pressure cuff to $>30 \mathrm{mmHg}$ above the base line SBP was maintained for 3 minutes, or until the $\mathrm{StO}_{2}$ decreased to a minimal threshold. The period of inflation was reported to be 3-4 seconds, while deflation time lasted $<0.5$ seconds. Shapiro and colleagues [37] reported using an automated tourniquet with inflation of the blood pressure cuff to $50 \mathrm{mmHg}$ above the SBP with the inflation lasting 3 minutes, after which time the cuff was rapidly removed. In addition, the arm position of the participants was only mentioned in one article [35], while in the study by Gómez et al. [36] the participants were described as resting in a semirecumbent position in a quiet environment. While Suhaimi et al. [35] reported that $93 \%$ of the participants were right hand dominant, no mention was made of the use of the dominant or nondominant hand/arm. Gómez and colleagues [36] included using the dominant hand of 15 volunteers during the study. Arm positioning on a table relative to the axillary region was described in the Gómez study [36], but not by the others [35, 37]. Suhaimi and coworkers [35] required the participants not to move the arm, hand, or fingers after a pulse oximetry probe was attached. Suhaimi et al. [35] allowed the subjects to stabilize movement for at least 5 minutes prior to starting the four serial VOT maneuvers. In the fourth VOT, the subjects squeezed a rubber ball between their index finger and thumb until cuff deflation. Therefore, it would appear that metabolic rate may have varied among participants and, subsequently, influenced $\mathrm{StO}_{2}$ measurements.

Lima and colleagues examined whether dynamic changes in $\mathrm{StO}_{2}$ values may be confounded by factors other than the desired biomarker of thenar muscle oxygenation [9]. Superficial skin cooling was imposed on 8 healthy volunteers while decreases in core temperature were prevented. The 
VOT protocol was performed prior to, during, and after cooling. The $\mathrm{StO}_{2}$ parameters consisted of the resting $\mathrm{StO}_{2}$ value and the desaturation and recovery rates of $\mathrm{StO}_{2}$. $\mathrm{StO}_{2}$ values and $\mathrm{StO}_{2}$ recovery rates significantly decreased in spite of preservation of muscle blood flow. These findings suggested that decreases in $\mathrm{StO}_{2}$ may mislead the bedside clinician to assume that tissue hypoxia is present, when this change may merely low blood flow to the skin and subcutaneous layers above the muscle capillary beds.

Gruartmoner and colleagues also investigated dynamic changes in $\mathrm{StO}_{2}$ measurements, in this case, during weaning from mechanical ventilation in 37 critically ill patients (Table 2, Study 4) [38]. A Vascular Occlusion Test (VOT) was used to measure sequential changes in tissue oxygen saturation, that is, the slopes of change in the rates of deoxygenation $\left(\mathrm{DeO}_{2}\right)$ during cuff inflation and reoxygenation $\left(\mathrm{ReO}_{2}\right)$ during deflation. A NIRS-derived thenar muscle oxygen consumption $\left(\operatorname{nirVO} \mathrm{V}_{2}\right)$ was calculated using what the researchers describe as the DeOx slope, tracking $\mathrm{StO}_{2}$ changes over time. An unsuccessful weaning process was associated with higher increases in $\mathrm{StO}_{2}$ deoxygenation rate $\left(\mathrm{DeO}_{2}\right)(P=0.04)$ and in local skeletal muscle oxygen consumption $\left(\operatorname{nirVO}_{2}\right)(P=0.04)$. The increases in the slope of change in the $\mathrm{DeO}_{2}$ were interpreted to indicate adverse acute redistribution of blood flow to the lungs during a weaning trial among patients who were unable to wean. The investigators suggest that if the metabolic demand of transitioning from mechanical ventilation to spontaneous ventilation cannot be met by increasing oxygen delivery, due to either limitations in cardiovascular reserve or increased work breathing, then the cardiovascular system addresses these excessive demands by increasing sympathetic tone to maximize cardiac output, while vasoconstriction redistributes blood flow away from the periphery and splanchnic circulation to the respiratory muscles.

Ives and coworkers [19] performed a retrospective analysis of prospective, within- subjects cohort study $(n=59)$ in order to evaluate whether $\mathrm{StO}_{2}$ measurements can better predict postoperative surgical site infections (SSIs) when compared to the National Nosocomial Infection Surveillance (NNIS) risk index, which the investigators report has limited accuracy (Table 2, Study 6). They measured $\mathrm{StO}_{2}$ preoperatively over the biceps and at the intended incision site and at 12,24 , and $48 \mathrm{~h}$ after surgery. There was a significant difference in $\mathrm{StO}_{2}$ values at the surgical site between patients who developed an SSI $(43 \%+18.1)$ and those who did not $(55 \%+22.0)$ at 12 and 48 hours after operation $(P=0.032$; $P=0.030$ ). While this study was adequately powered $a$ priori, well designed, and controlled with baseline measurements and a blinded outcome assessment, the $\mathrm{StO}_{2}$ values had large standard deviations with significant overlap.

3.7. Studies of Open-Heart Surgical Patients. Putnam and coworkers conducted a prospective, controlled study of sequential changes in multiple variables reflecting oxygen transport parameters, including cardiac output, mean arterial pressure, lactate, base deficit, and $\mathrm{StO}_{2}$ (Table 2, Study 12) [39]. The primary finding was that $\mathrm{StO}_{2}$ decreases preceded maximal changes in serum lactate by an average of 94 minutes. In a more rigorous study of 74 open-heart surgical patients, with a sample size based on an a priori power analysis, Sanders and researchers collected data at the time of induction of anesthesia at a rate of $1 / \mathrm{min}$, during first 20 minutes in ICU and at 2, 6, and 12 hours after surgery until extubation in the ICU or completion of total monitoring time of 24 hours (Table 2, Study 13) [40]. Postoperative morbidity was measured with the Postoperative Morbidity Survey (POMS). The investigators reported that mean $\mathrm{StO}_{2}$ measures during the first minutes of anesthesia and at 20 minutes in the ICU were lower in patients with postoperative morbidity scores than in patients without such morbidity on day 3 (72.9\% versus $85.5 \% ; P=0.009)$ and day $15(81.1 \%$ versus $87.6 \% ; P=0.04)$. While this study was supported by a grant from the manufacturer, the authors do not report whether the manufacturer had access to the data prior to publication.

\section{Discussion}

At the most fundamental level, the adequacy of tissue oxygenation is defined as the balance between the supply of and the demand for oxygen required for cellular function and metabolism at the cellular, organ, and systems levels. When tissue perfusion falls below the critical point at which blood flow to individual organs can no longer be maintained, shock is diagnosed by the progressive onset of hypotension $[7,41]$. Bedside clinicians assess end-organ tissue perfusion in critically ill patients by signs of altered mental status, peripheral skin color and warmth, capillary refill, pulse strength, mean arterial pressure, urinary output, and percent oxygen saturation of arterial hemoglobin $\left(\mathrm{SaO}_{2}\right)$ in the form of continuous pulse oximetry $\left(\mathrm{SpO}_{2}\right)$. However, these indicators may remain relatively normal during the early stages of shock, despite the fact that the patient's condition is deteriorating.

Although there is no gold standard for the clinical diagnosis of shock, increased serum lactate and lactate clearance continue to function as indicators of, respectively, the severity of tissue hypoxia and the adequacy of resuscitation from shock [41]. Yet many conditions of elevated lactate levels are not associated with anaerobic metabolism, including epinephrine administration, respiratory and metabolic alkalosis, and ethylene glycol intoxication; in addition, the physiological functions of recycled lactate at the cellular level are beneficial to the viability of red blood cells, cardiac muscle, striated muscle, astrocytes, and neurons [41]. Other conditions, such as diabetic ketoacidosis, impaired hepatic function, and large quantities of exogenous lactate used for resuscitation of traumatic injuries may also lead to elevated lactate levels [42]. In the healthy individual, the heart is a consumer of lactate up to maximal levels of myocardial oxygen consumption [43]. Bakker and colleagues propose that it would be more accurate to use the term lactate associated metabolic acidosis to describe the presence of elevated serum lactate levels in the presence of an abnormal arterial $\mathrm{pH}$. Bakker and colleagues point out that although there is only a weak, but statistically significant, relationship 
between arterial $\mathrm{pH}$ and serum lactate levels, the combined presence of metabolic acidosis and elevated serum lactate levels carry a high prognostic indicator of mortality [41].

\section{Conclusion}

The long-studied methodology of near-infrared spectroscopy (NIRS) has recently been applied in a novel technology designed to measure skeletal muscle tissue perfusion in critically ill patients. The basic assumption underlying this clinical application is that when tissue hypoxia occurs, the compensatory vasoconstriction that occurs in peripheral tissues will be signaled by a decrease in the $\mathrm{StO}_{2}$. Lima and colleagues emphasize that the peripheral circulation will be the first region to manifest tissue hypoperfusion and the last to show signs of reperfusion following resuscitation [6]. The research presented recommends that a cutoff $\mathrm{StO}_{2}$ value of less than $70 \%$ to $75 \%$ would represent a cause for concern as well as the need for troubleshooting for possible causes of reduced tissue perfusion. However, none of the study designs presented here have utilized randomized sampling, a control group, or sought to establish a cause-and-effect relationship between an intervention aimed at maintaining normal $\mathrm{StO}_{2}$ values and specific patient outcomes. Given that investments in new technology in intensive care unit budgets should be evidence based, more research is required using a consistent strategy for interventions in specific patient populations. In addition, we recommend that investigators clarify whether data was shared with the manufacturer of devices prior to publication. As with studies of new technical devices tested in clinical research, the studies under review were characterized by reasonable and expected limitations in design. These initial observational findings show modest promise, providing a necessary step in evaluating the clinical utility of a device designed to monitor a complex phenomenon of tissue oxygenation and its possible use in predicting complications and early identification of patients at risk for complications.

\section{Conflict of Interests}

The authors declare that there is no conflict of interests regarding the publication of this paper.

\section{References}

[1] H. B. Nguyen, "Central venous oxygen saturation: not easily replaced," Critical Care Medicine, vol. 41, no. 6, pp. 1570-1571, 2013.

[2] M. R. Pinsky, "Beyond global oxygen supply-demand relations: in search of measures of dysoxia," Applied Physiology in Intensive Care Medicine, vol. 2, pp. 319-321, 2012.

[3] R. J. Santora and F. A. Moore, "Monitoring trauma and intensive care unit resuscitation with tissue hemoglobin oxygen saturation," Critical Care, vol. 13, supplement 5, article S10, 2009.

[4] C. B. Cairns, F. A. Moore, J. B. Haenel et al., "Evidence for early supply independent mitochondrial dysfunction in patients developing multiple organ failure after trauma," Journal of Trauma-Injury Infection \& Critical Care, vol. 42, no. 3, pp. 532-536, 1997.
[5] M. Lipcsey, N. C. Z. Woinarski, and R. Bellomo, "Near infrared spectroscopy (NIRS) of the thenar eminence in anesthesia and intensive care," Annals of Intensive Care, vol. 2, article 11, 2012.

[6] A. Lima, J. van Bommel, T. C. Jansen, C. Ince, and J. Bakker, "Low tissue oxygen saturation at the end of early goal-directed therapy is associated with worse outcome in critically ill patients," Critical Care, vol. 13, supplement 5, article S13, 2009.

[7] S. M. Cohn, A. B. Nathens, F. A. Moore et al., "Tissue oxygen saturation predicts the development of organ dysfunction during traumatic shock resuscitation," Journal of Trauma-Injury Infection \& Critical Care, vol. 62, no. 1, pp. 44-55, 2007.

[8] R. Whittemore and K. Knafl, "The integrative review: updated methodology," Journal of Advanced Nursing, vol. 52, no. 5, pp. 546-553, 2005.

[9] A. Lima, M. E. van Genderen, E. Klijn, J. Bakker, and J. van Bommel, "Peripheral vasoconstriction influences thenar oxygen saturation as measured by near-infrared spectroscopy," Intensive Care Medicine, vol. 38, no. 4, pp. 606-611, 2012.

[10] R. R. Armola, A. M. Bourgault, M. A. Halm et al., "Upgrading the American Association of Critical-Care Nurses' evidenceleveling hierarchy," American Journal of Critical Care, vol. 18, no. 5, pp. 405-409, 2009.

[11] T. W. L. Scheeren, P. Schober, and L. A. Schwarte, "Monitoring tissue oxygenation by near infrared spectroscopy (NIRS): background and current applications," Journal of Clinical Monitoring and Computing, vol. 26, no. 4, pp. 279-287, 2012.

[12] B. Chance, "Optical method," Annual Review of Biophysics and Biophysical Chemistry, vol. 20, pp. 1-30, 1991.

[13] B. Chance and G. R. Williams, "The respiratory chain and oxidative phosphorylation," in Advances in Enzymology and Related Areas of Molecular Biology, A. Meister, Ed., vol. 17, pp. 65-134, Interscience, New York, NY, USA, 1956.

[14] M. Rosenthal, J. C. Lamanna, F. F. Jobsis, J. E. Levasseur, H. A. Kontos, and J. L. Patterson, "Effects of respiratory gases on cytochrome a in intact cerebral cortex: is there a critical $\mathrm{PO}_{2}$ ?" Brain Research, vol. 108, no. 1, pp. 143-154, 1976.

[15] F. F. Jobsis, "Method and apparatus for monitoring metabolism in body organs in vivo," Patent Application 17,727, Duke University, Durham, NC, USA, 1979.

[16] A. Pellicer and M. D. C. Bravo, "Near-infrared spectroscopy: a methodology-focused review," Seminars in Fetal and Neonatal Medicine, vol. 16, no. 1, pp. 42-49, 2011.

[17] Y. Hirano, K. Omura, Y. Tatsuzawa, J. Shimizu, Y. Kawaura, and G. Watanabe, "Tissue oxygen saturation during colorectal surgery measured by near-infrared spectroscopy: pilot study to predict anastomotic complications," World Journal of Surgery, vol. 30, no. 3, pp. 457-461, 2006.

[18] Y. Hirano, K. Omura, H. Yoshiba et al., "Near-infrared spectroscopy for assessment of tissue oxygen saturation of transplanted jejunal autografts in cervical esophageal reconstruction," Surgery Today, vol. 35, no. 1, pp. 67-72, 2005.

[19] C. L. Ives, D. K. Harrison, and G. S. Stansby, "Tissue oxygen saturation, measured by near-infrared spectroscopy, and its relationship to surgical-site infections," British Journal of Surgery, vol. 94, no. 1, pp. 87-91, 2007.

[20] A. J. Comerota, R. C. Throm, P. Kelly, and M. Jaff, “Tissue (muscle) oxygen saturation $\left(\mathrm{StO}_{2}\right)$ : a new measure of symptomatic lower-extremity arterial disease," Journal of Vascular Surgery, vol. 38, no. 4, pp. 724-729, 2003.

[21] D. E. Myers, L. D. Anderson, R. P. Seifert et al., "Noninvasive method for measuring local hemoglobin oxygen saturation in 
tissue using wide gap second derivative near-infrared spectroscopy," Journal of Biomedical Optics, vol. 10, no. 3, Article ID 034017, 2005.

[22] J. Creteur, "Muscle $\mathrm{StO}_{2}$ in critically ill patients," Current Opinion in Critical Care, vol. 14, no. 3, pp. 361-366, 2008.

[23] D. E. Skarda, K. E. Mulier, D. E. Myers, J. H. Taylor, and G. J. Beilman, "Dynamic near-infrared spectroscopy measurements in patients with severe sepsis," Shock, vol. 27, no. 4, pp. 348-353, 2007.

[24] J. M. Slater, T. A. Orszulak, and D. J. Cook, "Distribution and hierarchy of regional blood flow during hypothermic cardiopulmonary bypass," Annals of Thoracic Surgery, vol. 72, no. 2, pp. 542-547, 2001.

[25] J. Creteur, T. Carollo, G. Soldati, G. Buchele, D. de Backer, and J.-L. Vincent, "The prognostic value of muscle $\mathrm{StO}_{2}$ in septic patients," Intensive Care Medicine, vol. 33, no. 9, pp. 1549-1556, 2007.

[26] D. E. Skarda, K. E. Mulier, D. E. Myers, J. H. Taylor, and G. J. Beilman, "Dynamic near-infrared spectroscopy measurements in patients with severe sepsis," Shock, vol. 27, no. 4, pp. 348-353, 2007.

[27] G. J. Beilman, J. J. Blondet, T. R. Nelson et al., "Early hypothermia in severely injured trauma patients is a significant risk factor for multiple organ dysfunction syndrome but not mortality," Annals of Surgery, vol. 249, no. 5, pp. 845-850, 2009.

[28] D. G. Ikossi, M. M. Knudson, D. J. Morabito et al., "Continuous muscle tissue oxygenation in critically injured patients: a prospective observational study," Journal of Trauma-Injury Infection \& Critical Care, vol. 61, no. 4, pp. 780-790, 2006.

[29] J. Smith, S. Bricker, and B. Putnam, "Tissue oxygen saturation predicts the need for early blood transfusion in trauma patients," The American Surgeon, vol. 74, no. 10, pp. 1006-1011, 2008.

[30] R. P. Dellinger, M. M. Levy, A. Rhodes et al., "Surviving sepsis campaign: international guidelines for management of severe sepsis and septic shock," Critical Care Medicine, vol. 41, no. 2, pp. 580-637, 2013.

[31] M. Leone, S. Blidi, F. Antonini et al., "Oxygen tissue saturation is lower in nonsurvivors than in survivors after early resuscitation of septic shock," Anesthesiology, vol. 111, no. 2, pp. 366-371, 2009.

[32] J. Mesquida, G. Gruartmoner, M. L. Martínez et al., “Thenar oxygen saturation and invasive oxygen delivery measurements in critically ill patients in early septic shock," Shock, vol. 35, no. 5, pp. 456-459, 2011.

[33] K. E. Mulier, D. E. Skarda, J. H. Taylor et al., "Near-infrared spectroscopy in patients with severe sepsis: correlation with invasive hemodynamic measurements," Surgical Infections, vol. 9, no. 5, pp. 515-519, 2008.

[34] M. Poeze, “Tissue-oxygenation assessment using near-infrared spectroscopy during severe sepsis: confounding effects of tissue edema on $\mathrm{StO}_{2}$ values," Intensive Care Medicine, vol. 32, no. 5, pp. 788-789, 2006.

[35] F. M. Suhaimi, J. G. Chase, C. G. Pretty, R. Elliott, and G. M. Shaw, "Pulse oximeter concept for vascular occlusion test," International Journal of Medical, Pharmaceutical Science and Engineering, vol. 7, no. 11, pp. 29-33, 2013.

[36] H. Gómez, A. Torres, P. Polanco et al., "Use of non-invasive NIRS during a vascular occlusion test to assess dynamic tissue $\mathrm{O}_{2}$ saturation response," Intensive Care Medicine, vol. 34, no. 9, pp. 1600-1607, 2008.
[37] N. I. Shapiro, R. Arnold, R. Sherwin et al., "The association of near-infrared spectroscopy-derived tissue oxygenation measurements with sepsis syndromes, organ dysfunction and mortality in emergency department patients with sepsis," Critical Care, vol. 15, no. 5, article R223, 2011.

[38] G. Gruartmoner, J. Mesquida, M. L. Martinez et al., "Thenar oxygen saturation during weaning from mechanical ventilation: an observational study," European Respiratory Society, vol. 43, no. 1, pp. 213-220, 2013.

[39] B. Putnam, S. Bricker, P. Fedorka et al., "The correlation of near-infrared spectroscopy with changes in oxygen delivery in a controlled model of altered perfusion," The American Surgeon, vol. 73, no. 10, pp. 1017-1022, 2007.

[40] J. Sanders, I. S. Toor, T. M. Yurik, B. E. Keogh, M. Mythen, and H. E. Montgomery, "Tissue oxygen saturation and outcome after cardiac surgery," American Journal of Critical Care, vol. 20, no. 2, pp. 138-145, 2011.

[41] J. Bakker, M. W. N. Nijsten, and T. C. Jansen, "Clinical use of lactate monitoring in critically ill patients," Annals of Intensive Care, vol. 3, no. 1, article 12, 2013.

[42] D. Rixen and J. H. Siegel, "Bench-to-bedside review: oxygen debt and its metabolic correlates as quantifiers of the severity of hemorrhagic and posttraumatic shock," Critical Care, vol. 9, no. 5, pp. 441-453, 2005.

[43] W. C. Stanley, F. A. Recchia, and G. D. Lopaschuk, "Myocardial substrate metabolism in the normal and failing heart," Physiological Reviews, vol. 85, no. 3, pp. 1093-1129, 2005. 


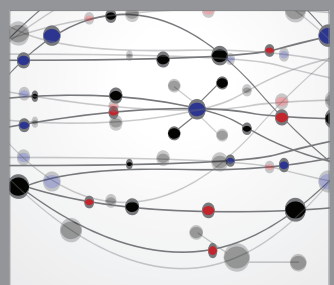

The Scientific World Journal
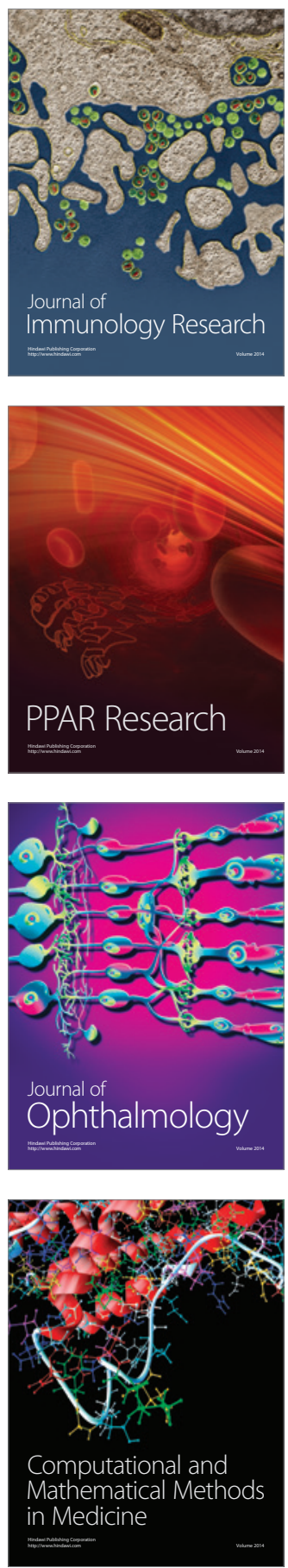

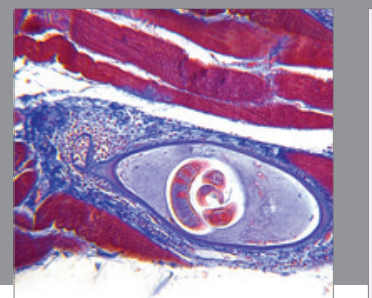

Gastroenterology

Research and Practice
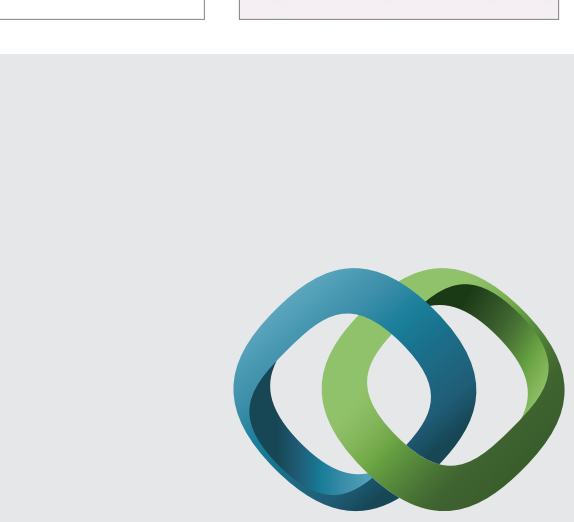

\section{Hindawi}

Submit your manuscripts at

http://www.hindawi.com
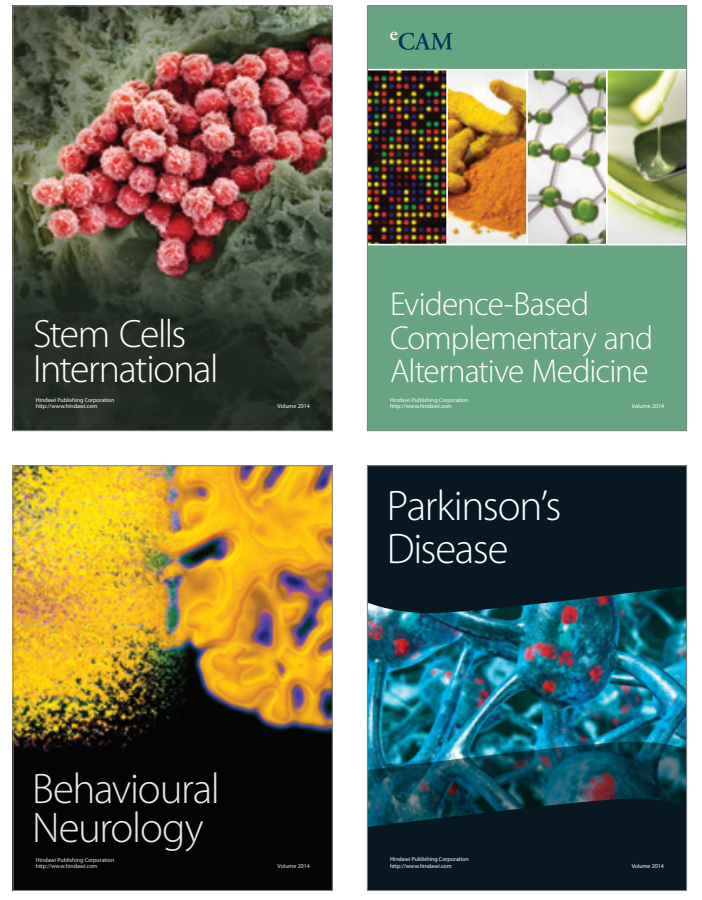
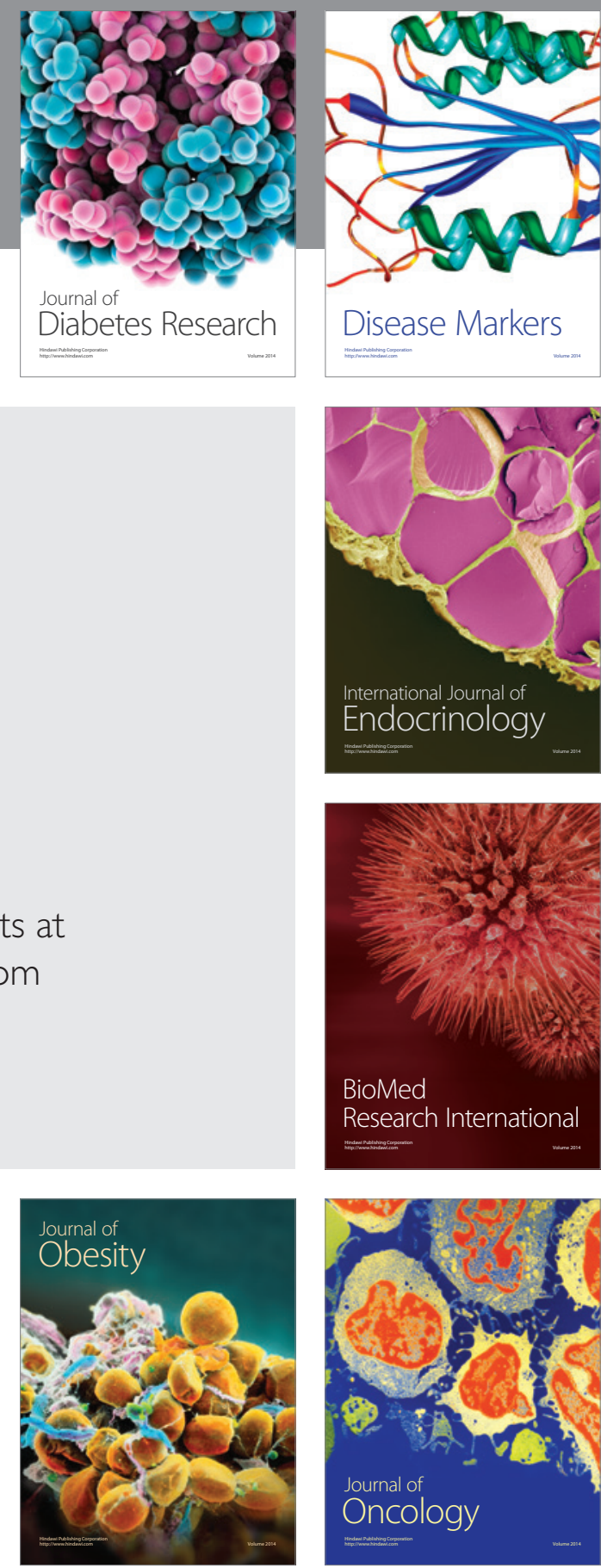

Disease Markers
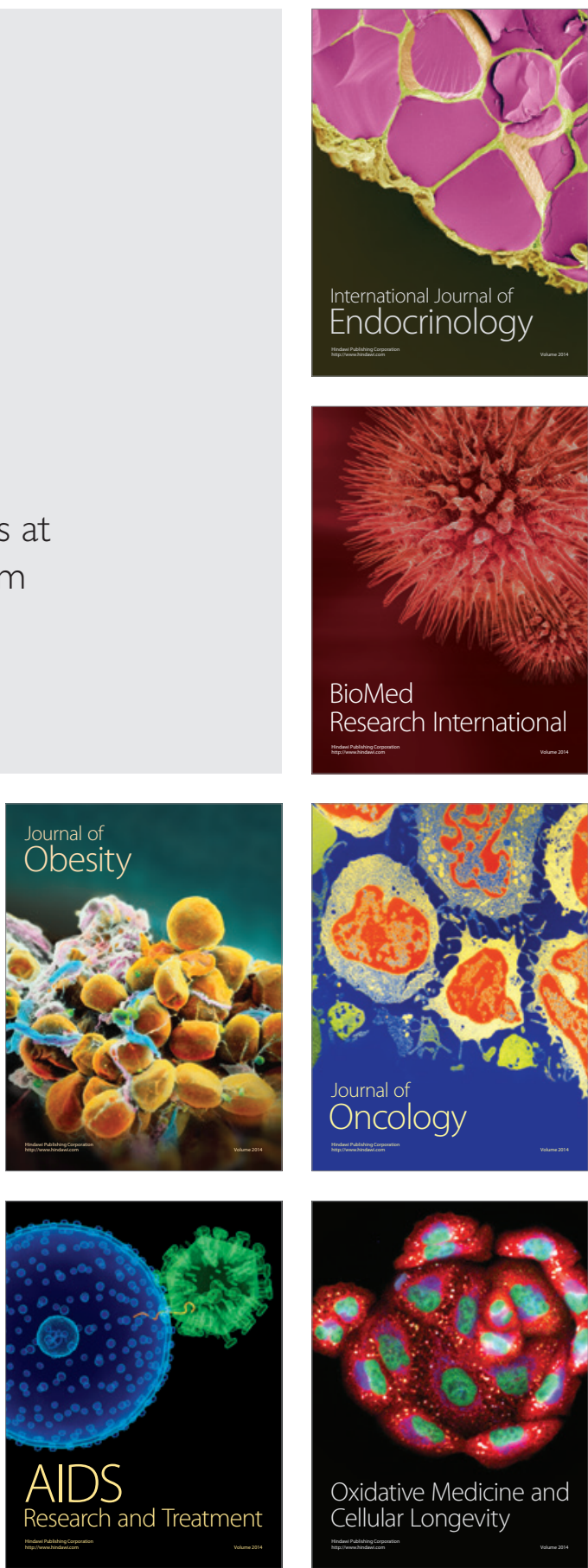